\title{
Effects of Diabetes Mellitus on the Mortality, Length of Hospital Stay and Number of Operations in Burn Patients
}

\author{
Sunmi Kim, Insuk Kwak ${ }^{1}$, Gyeong-Hun Park ${ }^{2}$ \\ Department of Family Medicine, Kangwon National University Hospital, Kangwon National University School of Medicine, Chuncheon, \\ ${ }^{1}$ Department of Anesthesiology, Hangang Sacred Heart Hospital, College of Medicine, Hallym University, Seoul, ${ }^{2}$ Department of \\ Dermatology, Dongtan Sacred Heart Hospital, College of Medicine, Hallym University, Hwaseong, Korea
}

Background: The effects of diabetes mellitus (DM) on mortality and morbidities in burn patients have not been sufficiently elucidated. Objective: The present study aimed to investigate the effects of DM on the mortality, length of hospital stay, and number of operations in burn patients. Methods: A retrospective cohort study was performed using medical records of 3,220 burn patients. Multiple logistic regression, linear regression, and Poisson regression models were used to determine whether DM increases mortality in patients with burn injury, whether DM prolongs length of hospital stay in burn survivors, and whether DM increases the number of operations in burn survivors, respectively. Results: After adjusting for potential confounding factors, DM significantly increased odds of death in burn patients (adjusted odds ratio 3.225 [95\% confidence interval $1.405 \sim 7.400], p=0.006$ ). $\mathrm{DM}$ also increased the mean length of hospital stay in burn

Received June 12, 2018, Revised August 3, 2018, Accepted for publication September 7, 2018

Corresponding author: Gyeong-Hun Park, Department of Dermatology, Dongtan Sacred Heart Hospital, College of Medicine, Hallym University, 7 Keunjaebong-gil, Hwaseong 18450, Korea. Tel: 82-31-8086-2839, Fax: 82-31-8086-2638, E-mail: borelalgebra@gmail.com ORCID: https://orcid.org/0000-0001-8890-8678

Insuk Kwak, Department of Anesthesiology, Hangang Sacred Heart Hospital, College of Medicine, Hallym University, 12 Beodeunaru-ro 7-gil, Yeongdeungpo-gu, Seoul 07247, Korea. Tel: 82-2-2639-5114, Fax: 82-2-2633-7571, E-mail: 031132@hallym.or.kr

ORCID: https://orcid.org/0000-0001-7091-9061

This is an Open Access article distributed under the terms of the Creative Commons Attribution Non-Commercial License (http://creativecommons. org/licenses/by-nc/4.0) which permits unrestricted non-commercial use, distribution, and reproduction in any medium, provided the original work is properly cited.

Copyright (c) The Korean Dermatological Association and The Korean Society for Investigative Dermatology survivors (adjusted mean ratio 1.312 [95\% confidence interval 1.198 1.437], $p<0.001)$. Furthermore, DM significantly increased the mean number of operations in burn survivors (adjusted mean ratio 1.576 [95\% confidence interval 1.391 1.785], $p<0.001)$. Conclusion: DM increases mortality, elongates hospital stay and makes more operations required in patients with burn injury. (Ann Dermatol 31(1) $51 \sim 58$, 2019)

-Keywords-

Burn, Diabetes mellitus, Morbidity, Mortality

\section{INTRODUCTION}

Diabetes mellitus (DM) is a prevalent metabolic disease involving about $10 \%$ of the general population ${ }^{1}$. It impairs vascular supply in both large and small blood vessels, peripheral nerve sensation, wound healing process, and immune function, which results in a wide variety of medical and surgical complications ${ }^{2}$. For recovery from burn injury, however, sufficient circulatory support, satisfactory restoration of the wound site, and protection against infection are required to prevent complications involving various organ systems. Thus burn patients with DM, in particular, may be at increased risk of unfavorable outcomes or complications ${ }^{3}$.

Previous studies have shown that DM increases mortality, complications, and the duration of intensive care unit stay and ventilator support among trauma patients ${ }^{4,5}$. In addition, a study on 58 pediatric burn patients revealed that the group with poor glucose control showed higher frequencies of death and positive blood culture, and a lower 
frequency of skin graft take without adjustment for confounding factors ${ }^{6}$. However, the effects of DM on mortality and morbidities in burn patients have not been sufficiently elucidated. The present study aimed to investigate the effects of DM on the mortality, length of hospital stay, and number of operations in bur patients.

\section{MATERIALS AND METHODS}

\section{Study population}

A retrospective cohort study was performed using medical records of all burn patients who were admitted to the Hangang Sacred Heart Hospital and discharged once between 1 January 2014 and 30 September 2016. During the period, a total of 5,207 patients were identified, and we sequentially excluded patients without systemic blood pressure measurement on the day of admission $(n=0,433)$, those without blood urea nitrogen measurement on the day of admission $(n=553)$, and those without serum creatinine measurement on the day of admission $(n=1)$. Finally, a total of 3,220 patients were eligible for the study (Fig. 1). This study was approved by the institutional review board of the Hangang Sacred Heart Hospital (IRB number. 2017-064).

\section{Outcomes of interest}

Mortality was defined as death during hospital stay. Length of hospital stay was defined as the number of days from admission to discharge. The number of operation was determined as total number of operation during the admission period.

\section{Variable definitions}

The presence or absence of DM was determined based on the history of patients. The patients who were diagnosed as DM or treated for DM were defined as having DM. The season at admission was defined as spring (March to May), summer (June to August), autumn (September to November), and winter (December to February). Body surface area was determined as the percentage of surface area involved by burn, and divided into less than $10 \%, 10 \%$ to $<20 \%$, $20 \%$ to $<30 \%, 30 \%$ to $<50,50 \%$ to $<70$, and $70 \%$ or more. Blood urea nitrogen $(\mathrm{mg} / \mathrm{dl})$, serum creatinine $(\mathrm{mg} / \mathrm{dl})$ and systolic blood pressure levels $(\mathrm{mmHg})$ were based on the initial measurement results on the day of admission.

\section{Statistical analyses}

Demographic and clinical characteristics of the study population were summarized as mean \pm standard deviation and range for continuous variables including age, number of operation, length of hospital stay, blood urea nitrogen, and serum creatinine, and as number and proportion for categorical variables including sex, DM, season at admission, body surface area, and systolic blood pressure in both survival and death groups.

Simple and multiple logistic regression analyses were sequentially performed to determine whether DM increases mortality in burn patients or not after adjustment for potential confounders. Simple and multiple linear regression analyses were sequentially performed to determine whether DM prolongs length of hospital stay in burn survivors after adjustment for potential confounders. Based on the normality in a Q-Q plot, the log-transformed length of hospital stay was used for the analyses. Simple and multiple Poisson regression models with log link function were sequentially performed to determine whether DM increases the number of operations in burn survivors after adjustment for potential confounders.

All of statistical analyses were performed using the statistical software package $R$ version 3.3.1 (The R Foundation for Statistical Computing, Vienna, Austria). Two-sided $p$ -

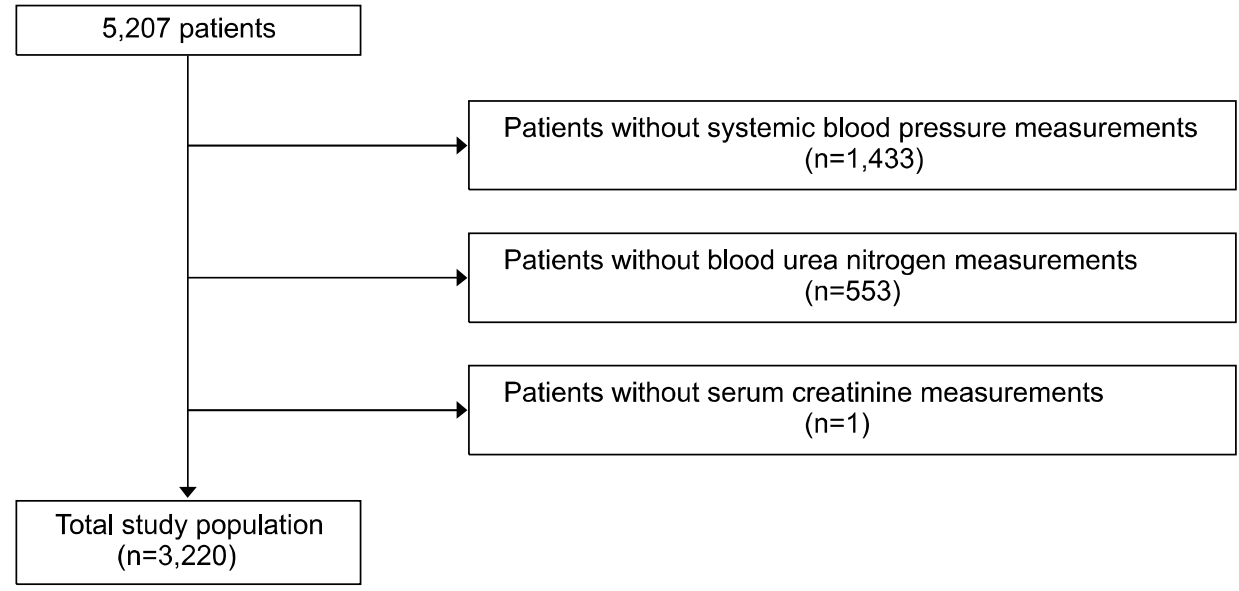

Fig. 1. Flowchart of the study population. 
alues less than 0.05 were considered as statistically significant.

\section{RESULTS}

\section{Characteristics of the study population}

Table 1 summarizes demographic and clinical characteristics of the study population. Compared to burn patients without DM, the those with DM showed significantly a higher mean age $(p<0.001)$, higher mean blood urea nitrogen and serum creatinine levels ( $p<0.001$ for both), more frequent death $(p=0.005)$, longer mean hospital stay $(p<0.001)$, higher mean number of operations $(p<0.001)$, and different distribution pattern of season at admission $(p=0.043)$, and systolic blood pressure $(p<0.001)$.

\section{DM increases mortality in burn patients (Table 2)}

A simple logistic regression analysis showed that the odds of death was significantly higher in DM patients compared with those without DM (odds ratio 2.061 [95\% confidence interval 1.280 3.319], $p=0.003$ ). However, other factors including sex, age, season at admission, body surface area, blood urea nitrogen, serum creatinine, and systolic blood pressure were also significantly associated with mortality in burn patients ( $p=0.010$ for season at admission, and $p<0.001$ for the others). To adjust for the effect of these potential confounding factors, we conducted multiple logistic regression analyses, which confirmed that DM significantly increases odds of death in burn patients (adjusted odds ratio 3.225 [95\% confidence interval 1.405 7.400], $p=0.006$ ).

\section{DM increases length of hospital stay in burn survivors (Table 3)}

A simple linear regression analysis showed that the mean length of hospital stay in survived burn patients was significantly longer in those with DM compared with those without DM (mean ratio 1.430 [95\% confidence interval $1.298 \sim 1.575], p<0.001)$. However, other factors including sex, age, season at admission, body surface area, blood urea nitrogen, serum creatinine, and systolic blood pressure were also significantly associated with the length of hospital stay in survived burn patients $(p=0.026$ for season at admission, and $p<0.001$ for the others). To adjust for the effect of these potential confounding factors, we performed multiple linear regression analyses, which

Table 1. Demographic and clinical characteristics of the study population

\begin{tabular}{|c|c|c|c|c|}
\hline \multirow{2}{*}{ Variable } & \multirow{2}{*}{ Category } & \multicolumn{2}{|c|}{ Diabetes mellitus } & \multirow{2}{*}{$p$-value* } \\
\hline & & Absent $(n=2,902)$ & Present $(n=318)$ & \\
\hline Age (yr) & & $45.60 \pm 16.77(11 \sim 96)$ & $61.90 \pm 12.55(23 \sim 91)$ & $<0.001$ \\
\hline \multirow[t]{2}{*}{ Sex } & Female & $1,240(42.7)$ & $127(39.9)$ & 0.370 \\
\hline & Male & $1,662(57.3)$ & $191(60.1)$ & \\
\hline \multirow[t]{4}{*}{ Season } & Summer & $863(29.7)$ & $81(25.5)$ & 0.043 \\
\hline & Autumn & $508(17.5)$ & $44(13.8)$ & \\
\hline & Spring & $851(29.3)$ & $101(31.8)$ & \\
\hline & Winter & $680(23.4)$ & $92(28.9)$ & \\
\hline \multirow[t]{6}{*}{ Body surface area (\%) } & $<10$ & $2,279(78.5)$ & $248(78.0)$ & 0.997 \\
\hline & 10 to $<20$ & $319(11.0)$ & $36(11.3)$ & \\
\hline & 20 to $<30$ & $115(4.0)$ & $14(4.4)$ & \\
\hline & 30 to $<50$ & $98(3.4)$ & $11(3.5)$ & \\
\hline & 50 to $<70$ & $42(1.4)$ & $4(1.3)$ & \\
\hline & $\geq 70$ & $49(1.7)$ & $5(1.6)$ & \\
\hline Blood urea nitrogen $(\mathrm{mg} / \mathrm{dL})$ & & $13.23 \pm 6.00(2.30 \sim 94.20)$ & $17.38 \pm 10.80(4.30 \sim 118.00)$ & $<0.001$ \\
\hline Creatinine $(\mathrm{mg} / \mathrm{dL})$ & & $0.74 \pm 0.35(0.14 \sim 7.71)$ & $1.08 \pm 1.39(0.28 \sim 10.48)$ & $<0.001$ \\
\hline \multirow[t]{4}{*}{ Systolic blood pressure $(\mathrm{mmHg})$} & 110 to $<120$ & $708(24.4)$ & $51(16.0)$ & $<0.001$ \\
\hline & 120 to $<130$ & $992(34.2)$ & $93(29.2)$ & \\
\hline & $\geq 130$ & $922(31.8)$ & $156(49.1)$ & \\
\hline & $<110$ & $280(9.6)$ & $18(5.7)$ & \\
\hline \multirow[t]{2}{*}{ Survival } & Survived & $2,801 \quad(96.5)$ & $296(93.1)$ & 0.005 \\
\hline & Dead & 101 & $22(6.9)$ & \\
\hline Length of stay & & $21.03 \pm 18.65(1 \sim 165)$ & $31.54 \pm 30.64 \quad(1 \sim 195)$ & $<0.001$ \\
\hline Number of operation & & $0.77 \pm 1.90(0 \sim 39)$ & $1.12 \pm 2.01 \quad(0 \sim 20)$ & $<0.001$ \\
\hline
\end{tabular}

Values are presented as mean \pm standard deviation (range) or number (\%). *Fisher exact test for categorical variables, and Wilcoxon rank sum test or Kruskal-Wallis test for continuous variables. 
Table 2. Effects of diabetes mellitus on the mortality in burn patients $(n=3,220)$

\begin{tabular}{|c|c|c|c|c|c|c|}
\hline \multirow{2}{*}{ Variable } & \multirow{2}{*}{ Category } & \multirow{2}{*}{ Value* } & \multicolumn{2}{|c|}{ Simple logistic regression analyses } & \multicolumn{2}{|c|}{ Multiple logistic regression analysis } \\
\hline & & & OR $(95 \% \mathrm{Cl})$ & $p$-value & Adjusted OR $(95 \% \mathrm{Cl})$ & $p$-value \\
\hline \multirow[t]{2}{*}{ Sex } & Female & 22/1,367 (1.6) & Reference & - & & \\
\hline & Male & $101 / 1,853(5.5)$ & $3.524(2.211 \sim 5.619)$ & $<0.001$ & & \\
\hline Age (year) & & & $1.036(1.025 \sim 1.048)$ & $<0.001$ & $1.050(1.028 \sim 1.073)$ & $<0.001$ \\
\hline \multirow{2}{*}{$\begin{array}{l}\text { Diabetes } \\
\text { mellitus }\end{array}$} & Absent & $101 / 2,902(3.5)$ & Reference & - & Reference & - \\
\hline & Present & $22 / 318(6.9)$ & $2.061(1.280 \sim 3.319)$ & 0.003 & $3.225(1.405 \sim 7.400)$ & 0.006 \\
\hline \multirow[t]{5}{*}{ Season } & & & & 0.010 & & 0.006 \\
\hline & Summer & 29/944 (3.1) & Reference & - & Reference & - \\
\hline & Autumn & $12 / 552(2.2)$ & $0.701(0.355 \sim 1.385)$ & 0.307 & $1.682(0.506 \sim 5.587)$ & 0.396 \\
\hline & Spring & $51 / 952(5.4)$ & $1.786(1.122 \sim 2.843)$ & 0.015 & $4.162(1.732 \sim 9.999)$ & 0.001 \\
\hline & Winter & $31 / 772(4.0)$ & $1.320(0.788 \sim 2.210)$ & 0.291 & $3.967(1.537 \sim 10.237)$ & 0.004 \\
\hline \multirow{7}{*}{$\begin{array}{l}\text { Body surface } \\
\text { area }(\%)\end{array}$} & & & & $<0.001$ & & $<0.001$ \\
\hline & $<10$ & $7 / 2,527(0.3)$ & Reference & - & Reference & - \\
\hline & 10 to $<20$ & 3/355 (0.8) & $3.068(0.790 \sim 11.919)$ & 0.105 & $3.567(0.858 \sim 14.827)$ & 0.080 \\
\hline & 20 to $<30$ & $7 / 129(5.4)$ & $20.656(7.133 \sim 59.814)$ & $<0.001$ & $23.141(7.010 \sim 76.397)$ & $<0.001$ \\
\hline & 30 to $<50$ & 33/109 (30.3) & $156.316(67.022 \sim 364.577)$ & $<0.001$ & $214.911(77.356 \sim 597.065)$ & $<0.001$ \\
\hline & 50 to $<70$ & 23/46 (50.0) & $360.000(140.577 \sim 921.916)$ & $<0.001$ & $\begin{array}{c}774.465 \\
(238.412 \sim 2,515.794)\end{array}$ & $<0.001$ \\
\hline & $\geq 70$ & $50 / 54(92.6)$ & $\begin{array}{c}4,500.000 \\
(1,276.538 \sim 15,863.220)\end{array}$ & $<0.001$ & $\begin{array}{c}16,303.135 \\
(3,511.515 \sim 75,691.602)\end{array}$ & $<0.001$ \\
\hline $\begin{array}{l}\text { Blood urea } \\
\text { nitrogen } \\
\text { (mg/dL) }\end{array}$ & & & $1.087(1.068 \sim 1.106)$ & $<0.001$ & $1.051(1.029 \sim 1.075)$ & $<0.001$ \\
\hline $\begin{array}{l}\text { Creatinine } \\
(\mathrm{mg} / \mathrm{dL})\end{array}$ & & & $1.612(1.387 \sim 1.872)$ & $<0.001$ & & \\
\hline \multirow{5}{*}{$\begin{array}{l}\text { Systolic } \\
\text { blood pressure } \\
(\mathrm{mmHg})\end{array}$} & & & & $<0.001$ & & $<0.001$ \\
\hline & 110 to $<120$ & 7/759 (0.9) & Reference & - & Reference & - \\
\hline & 120 to $<130$ & 21/1,085 (1.9) & $2.120(0.897 \sim 5.013)$ & 0.087 & $1.455(0.374 \sim 5.666)$ & 0.589 \\
\hline & $\geq 130$ & $68 / 1,078(6.3)$ & $7.233(3.303 \sim 15.836)$ & $<0.001$ & $1.723(0.504 \sim 5.888)$ & 0.386 \\
\hline & $<110$ & $27 / 298(9.1)$ & $10.703(4.608 \sim 24.862)$ & $<0.001$ & $9.236(2.344 \sim 36.391)$ & 0.001 \\
\hline
\end{tabular}

OR: odds ratio, $\mathrm{Cl}$ : confidence interval. *Number of death/number of patients (percentage).

showed that DM significantly increases the mean length of hospital stay in burn survivors (adjusted mean ratio 1.312 [95\% confidence interval 1.198 1.437], $p<0.001$ ).

\section{DM increases number of operations in burn survivors (Table 4)}

A simple Poisson regression analysis showed that the mean number of operations in survived burn patients was significantly higher in those with DM compared with those without DM (mean ratio 1.463 [95\% confidence interval 1.302 1.643], $p<0.001$ ). However, other factors including sex, season at admission, body surface area, blood urea nitrogen, serum creatinine, and systolic blood pressure were also significantly associated with the number of operations in survived burn patients $(p=0.010$ for blood urea nitrogen, and $p<0.001$ for the others). To ad- just for the effect of these potential confounding factors, we did multiple Poisson regression analyses, which proved that DM significantly increases the mean number of operations in burn survivors (adjusted mean ratio 1.576 [95\% confidence interval $1.391 \sim 1.785], p<0.001$ ).

\section{DISCUSSION}

Previous studies have repeatedly failed to show the effect of DM on the mortality of burn patients ${ }^{2,3,7,8}$. Several reports of increased morbidities in burn patients with DM were also based on the results of simple comparisons between those with and without DM without adjustment for confounding factors ${ }^{2,3,7-10}$. McCampbell et al. ${ }^{2}$ reported that diabetic burn patients have longer length of hospital stay and higher possibilities for skin graft, burn-related 
Table 3. Effects of diabetes mellitus on length of hospital stay in burn survivors $(n=3,097)$

\begin{tabular}{|c|c|c|c|c|c|c|}
\hline \multirow[b]{2}{*}{ Variable } & \multirow[b]{2}{*}{ Category } & \multirow[b]{2}{*}{ Value $^{\dagger}$} & \multicolumn{2}{|c|}{ Simple linear regression analyses* } & \multicolumn{2}{|c|}{ Multiple linear regression analysis* } \\
\hline & & & Mean ratio $(95 \% \mathrm{Cl})$ & $p$-value & $\begin{array}{c}\text { Adjusted mean ratio } \\
(95 \% \mathrm{Cl})\end{array}$ & $p$-value \\
\hline \multirow[t]{2}{*}{ Sex } & Female & $19.6 \pm 18.4$ & Reference & - & Reference & - \\
\hline & Male & $24.1 \pm 21.2$ & $1.205(1.137 \sim 1.276)$ & $<0.001$ & $1.081(1.023 \sim 1.142)$ & 0.005 \\
\hline Age $(y r)$ & & & $1.008(1.006 \sim 1.009)$ & $<0.001$ & $1.005(1.003 \sim 1.006)$ & $<0.001$ \\
\hline \multirow[t]{2}{*}{ Diabetes mellitus } & Absent & $21.2 \pm 18.7$ & Reference & - & Reference & - \\
\hline & Present & $31.4 \pm 29.3$ & $1.430(1.298 \sim 1.575)$ & $<0.001$ & $1.312(1.198 \sim 1.437)$ & $<0.001$ \\
\hline \multirow[t]{5}{*}{ Season } & & & & 0.026 & & 0.001 \\
\hline & Summer & $20.7 \pm 18.4$ & Reference & - & Reference & - \\
\hline & Autumn & $20.9 \pm 16.8$ & $1.024(0.939 \sim 1.117)$ & 0.585 & $1.046(0.969 \sim 1.130)$ & 0.251 \\
\hline & Spring & $22.4 \pm 20.6$ & $1.056(0.980 \sim 1.138)$ & 0.153 & $1.084(1.014 \sim 1.159)$ & 0.018 \\
\hline & Winter & $24.5 \pm 23.4$ & $1.126(1.040 \sim 1.218)$ & 0.003 & $1.150(1.071 \sim 1.233)$ & $<0.001$ \\
\hline \multirow[t]{7}{*}{ Body surface area (\%) } & & & & $<0.001$ & & $<0.001$ \\
\hline & $<10$ & $18.5 \pm 17.6$ & Reference & - & Reference & - \\
\hline & 10 to $<20$ & $32.2 \pm 19.4$ & $2.006(1.848 \sim 2.179)$ & $<0.001$ & $1.924(1.773 \sim 2.089)$ & $<0.001$ \\
\hline & 20 to $<30$ & $41.2 \pm 19.9$ & $2.653(2.320 \sim 3.034)$ & $<0.001$ & $2.558(2.240 \sim 2.920)$ & $<0.001$ \\
\hline & 30 to $<50$ & $52.5 \pm 21.1$ & $3.499(2.957 \sim 4.142)$ & $<0.001$ & $3.335(2.823 \sim 3.939)$ & $<0.001$ \\
\hline & 50 to $<70$ & $62.3 \pm 29.8$ & $4.101(3.029 \sim 5.553)$ & $<0.001$ & $4.014(2.978 \sim 5.410)$ & $<0.001$ \\
\hline & $\geq 70$ & $54.5 \pm 75.3$ & $1.513(0.733 \sim 3.121)$ & 0.263 & $1.598(0.786 \sim 3.251)$ & 0.195 \\
\hline Blood urea nitrogen $(\mathrm{mg} / \mathrm{dL})$ & & & $1.008(1.003 \sim 1.013)$ & $<0.001$ & & \\
\hline Creatinine $(\mathrm{mg} / \mathrm{dL})$ & & & $1.114(1.056 \sim 1.174)$ & $<0.001$ & & \\
\hline \multirow[t]{5}{*}{ Systolic blood pressure $(\mathrm{mmHg})$} & & & & $<0.001$ & & 0.058 \\
\hline & 110 to $<120$ & $19.5 \pm 17.2$ & Reference & - & Reference & - \\
\hline & 120 to $<130$ & $20.5 \pm 17.9$ & $1.062(0.985 \sim 1.145)$ & 0.115 & $1.019(0.952 \sim 1.091)$ & 0.589 \\
\hline & $\geq 130$ & $26.5 \pm 23.9$ & $1.341(1.243 \sim 1.447)$ & $<0.001$ & $1.095(1.019 \sim 1.177)$ & 0.013 \\
\hline & $<110$ & $19.7 \pm 18.2$ & $0.990(0.886 \sim 1.108)$ & 0.866 & $1.023(0.925 \sim 1.131)$ & 0.663 \\
\hline
\end{tabular}

$\mathrm{Cl}$ : confidence interval. *Based on the normality in a Q-Q plot, the log-transformed length of hospital stay was used in the linear regression analyses. ${ }^{\dagger}$ Mean \pm standard deviation of length of hospital stay (day).

procedure, infection, partial graft slough, and regraft without adjustment for confounding factors. They showed no significant difference in mortality between diabetic and nondiabetic burn patients ${ }^{2}$. Memmel et al. ${ }^{8}$ also described that frequencies of sepsis, community-acquired burn wound cellulitis, or urinary tract infection were higher in diabetic burn patients. However, the results were not adjusted for confounders, and mortality was not significantly higher in diabetic burn patients. In a retrospective study on 207 patients with lower extremity burn injury, diabetic patients showed higher burn intensive care unit admission rates, a longer length of hospital stay, and a higher frequency of renal failure, but they did not consider effects of potential confounders. Furthermore, they also reported no significant mortality difference between diabetic and nondiabetic patients ${ }^{7}$. In a recent study on 586 burn patients, univariable analyses showed higher frequencies of wound infection, severe renal impairment, and unplanned readmission, a longer hospital stay, and more operations in the diabetic group. However, multivariable analyses disclosed that DM was associated with neither mortality nor un- planned readmission. DM was even associated with a significantly lower rate of admission to intensive care unit in the multivariable analysis ${ }^{3}$. Thourani et al. ${ }^{10}$ also described a lower success rate of split-thickness skin graft in diabetics based on a simple comparison between diabetic and nondiabetic burn patients, but the difference was abrogated by multivariable analyses adjusting for confounding factors.

In contrast, our retrospective cohort study involving more than 3,000 burn patients showed that DM significantly increases mortality of burn patients, and that, even in case of survival, DM also increases both the length of hospital stay and the number of operations through multivariable analyses adjusting for potential confounding factors. To the best of our knowledge, this is the first study to prove the confounder-adjusted effect of DM on the mortality and morbidities in patients with burn injury. Compared with previous studies, our present study included a considerably higher number of patients, who were all hospitalized. Such characteristics of the study population would have increased the power to detect the effects of DM. 
Table 4. Effects of diabetes mellitus on the number of operations in burn survivors $(n=3,097)$

\begin{tabular}{|c|c|c|c|c|c|}
\hline \multirow{2}{*}{ Variable } & \multirow{2}{*}{ Category } & \multicolumn{2}{|c|}{ Simple Poisson regression analyses* } & \multicolumn{2}{|c|}{ Multiple Poisson regression analysis* } \\
\hline & & Mean ratio $(95 \% \mathrm{Cl})$ & $p$-value & Adjusted mean ratio $(95 \% \mathrm{Cl})$ & $p$-value \\
\hline \multirow[t]{2}{*}{ Sex } & Female & Reference & - & & \\
\hline & Male & $1.402(1.290 \sim 1.523)$ & $<0.001$ & & \\
\hline Age (yr) & & $1.001(0.999 \sim 1.004)$ & 0.311 & $0.994(0.991 \sim 0.997)$ & $<0.001$ \\
\hline \multirow[t]{2}{*}{ Diabetes mellitus } & Absent & Reference & - & Reference & - \\
\hline & Present & $1.463(1.302 \sim 1.643)$ & $<0.001$ & $1.576(1.391 \sim 1.785)$ & $<0.001$ \\
\hline \multirow[t]{5}{*}{ Season } & & & $<0.001$ & & $<0.001$ \\
\hline & Summer & Reference & - & Reference & - \\
\hline & Autumn & $1.031(0.910 \sim 1.169)$ & 0.629 & $1.112(0.979 \sim 1.262)$ & 0.102 \\
\hline & Spring & $1.107(0.995 \sim 1.232)$ & 0.062 & $1.243(1.116 \sim 1.385)$ & $<0.001$ \\
\hline & Winter & $1.365(1.227 \sim 1.519)$ & $<0.001$ & $1.499(1.345 \sim 1.670)$ & $<0.001$ \\
\hline \multirow[t]{7}{*}{ Body surface area (\%) } & & & $<0.001$ & & $<0.001$ \\
\hline & $<10$ & Reference & - & Reference & - \\
\hline & 10 to $<20$ & $2.572(2.313 \sim 2.860)$ & $<0.001$ & $2.722(2.441 \sim 3.034)$ & $<0.001$ \\
\hline & 20 to $<30$ & $4.851(4.279 \sim 5.498)$ & $<0.001$ & $4.968(4.376 \sim 5.639)$ & $<0.001$ \\
\hline & 30 to $<50$ & $7.091(6.225 \sim 8.077)$ & $<0.001$ & $7.113(6.231 \sim 8.120)$ & $<0.001$ \\
\hline & 50 to $<70$ & $8.946(7.332 \sim 10.915)$ & $<0.001$ & $9.781(7.979 \sim 11.990)$ & $<0.001$ \\
\hline & $\geq 70$ & $9.798(6.300 \sim 15.238)$ & $<0.001$ & $11.429(7.315 \sim 17.856)$ & $<0.001$ \\
\hline Blood urea nitrogen $(\mathrm{mg} / \mathrm{dL})$ & & $1.008(1.002 \sim 1.013)$ & 0.010 & $1.009(1.003 \sim 1.014)$ & 0.003 \\
\hline Creatinine $(\mathrm{mg} / \mathrm{dL})$ & & $1.103(1.046 \sim 1.163)$ & $<0.001$ & & \\
\hline \multirow[t]{5}{*}{ Systolic blood pressure $(\mathrm{mmHg})$} & & & $<0.001$ & & 0.005 \\
\hline & 110 to $<120$ & Reference & - & Reference & - \\
\hline & 120 to $<130$ & $1.037(0.925 \sim 1.163)$ & 0.529 & $0.989(0.882 \sim 1.109)$ & 0.848 \\
\hline & $\geq 130$ & $1.504(1.351 \sim 1.675)$ & $<0.001$ & $1.105(0.988 \sim 1.236)$ & 0.080 \\
\hline & $<110$ & $1.253(1.070 \sim 1.467)$ & 0.005 & $1.252(1.068 \sim 1.467)$ & 0.006 \\
\hline
\end{tabular}

$\mathrm{Cl}$ : confidence interval. ${ }^{*} \mathrm{~A}$ logarithmic link function was used in the Poisson regression analyses.

The effects of other prognostic factors were also confirmed in this study. The age and body surface area are wellknown prognostic factors for outcomes of patients with burn injury, and commonly included in many prognostic scoring systems ${ }^{11-14}$. Our study confirmed that the age and body surface area are significant prognostic factors for mortality, length of hospital stay, and the number of operation. Sex is included as a prognostic factor in the abbreviated burn severity index ${ }^{14}$, but not in more recently developed scoring systems ${ }^{11-13}$. Our multivariable analyses showed that males had longer hospital stay than females, but sex was not associated with mortality and the number of operation. The present study showed that higher levels of blood urea nitrogen were associated with higher mortality, which is consistent with results of a previous cohort study which showed that acute renal injury independently predicts mortality in patients with major burns ${ }^{15}$. A study on 70 burn patients aged 60 years or more reported that hypertension impaired the probability of survival ${ }^{16}$. Our results also showed the trend of increase in mortality as the level of systolic blood pressure increased when it was higher than $110 \mathrm{mmHg}$, although it was not statistically significant. On the contrary, the low blood pressure was significantly associated with higher mortality, which seems to result from death from circulatory failure after burn injury. In addition, higher blood pressure was significantly associated with longer hospital stay.

An interesting result of this study was that the outcome of burn injury was significantly different according to season even after adjusting for potential confounders. In particular, all of the mortality, length of hospital stay, and number of operations were consistently higher in spring and winter. The reason for this seasonality is not clear. There have been studies which showed a significant difference in the incidence of burns according to season, but mortality was not different between seasons ${ }^{17,18}$. A previous study in United States reported the seasonal variation in surgical outcomes, although it is not limited to burn patients ${ }^{19}$. The study showed that both postoperative morbidity and mortality were significantly higher in July to August compared with April to June. In United States, July to August is the period when there is a marked influx of new trainees in most medical centers. This is consistent with unfavorable outcomes in spring in this study, because new trainees start their roles in spring in Korea. In winter, there may be a relative shortage of manpower be- 
cause male trainees are drafted into the army in Korea. The seasonal tendency of higher mortality during winter may also partially explain the worse outcomes in this study ${ }^{20}$. However, further studies are needed to elucidate the seasonal changes in burn outcomes because we cannot exclude the possibilities of effects of other seasonal factors including environmental changes.

This study has several limitations. First, the findings are based on the data of a single center. However, this weakness may have been redeemed by the status of our hospital as a referral burn center and the large scale of this study. The Hangang Sacred Heart Hospital is one of the largest burn centers in Korea, and this study analyzed the data of more than 3,000 patients. Second, all patients were not objectively assessed for the status of DM, and thus there may be a possibility of under-diagnosis of DM. If patients with mild DM were more selectively missed out, the effect of DM on clinical outcomes may have been overestimated. Third, this study does not provide the reason of the poor clinical outcomes in burn patients with DM. Further studies would be needed to compare the duration of antimicrobial therapy and frequencies of skin infection and sepsis between burn patients with and without DM.

In summary, the present study showed that DM increases mortality, elongates hospital stay and makes more operations required in patients with burn injury. These results mean that DM may be a useful prognostic factor to predict the outcome of burn patients, and suggest that more careful treatment and monitoring are required for burn patients with DM.

\section{CONFLICTS OF INTEREST}

The authors have nothing to disclose.

\section{ORCID}

Sunmi Kim, https://orcid.org/0000-0002-8801-3353

Insuk Kwak, https://orcid.org/0000-0001-7091-9061

Gyeong-Hun Park, https://orcid.org/0000-0001-8890-8678

\section{REFERENCES}

1. Danaei G, Finucane MM, Lu Y, Singh GM, Cowan MJ, Paciorek CJ, et al. National, regional, and global trends in fasting plasma glucose and diabetes prevalence since 1980: systematic analysis of health examination surveys and epidemiological studies with 370 country-years and 2.7 million participants. Lancet 2011;378:31-40.

2. McCampbell B, Wasif N, Rabbitts A, Staiano-Coico L, Yurt
RW, Schwartz S. Diabetes and burns: retrospective cohort study. J Burn Care Rehabil 2002;23:157-166.

3. Low ZK, Ng WY, Fook-Chong S, Tan BK, Chong SJ, Hwee J, et al. Comparison of clinical outcomes in diabetic and non-diabetic burns patients in a national burns referral centre in southeast Asia: a 3-year retrospective review. Burns 2017; 43:436-444.

4. Ahmad R, Cherry RA, Lendel I, Mauger DT, Service SL, Texter LJ, et al. Increased hospital morbidity among trauma patients with diabetes mellitus compared with age- and injury severity score-matched control subjects. Arch Surg 2007;142:613-618.

5. Liou DZ, Singer MB, Barmparas G, Harada MY, Mirocha J, Bukur $M$, et al. Insulin-dependent diabetes and serious trauma. Eur J Trauma Emerg Surg 2016;42:491-496.

6. Gore DC, Chinkes D, Heggers J, Herndon DN, Wolf SE, Desai M. Association of hyperglycemia with increased mortality after severe burn injury. J Trauma 2001;51: 540-544.

7. Kimball Z, Patil S, Mansour H, Marano MA, Petrone SJ, Chamberlain RS. Clinical outcomes of isolated lower extremity or foot burns in diabetic versus non-diabetic patients: a 10-year retrospective analysis. Burns 2013;39: 279-284.

8. Memmel H, Kowal-Vern A, Latenser BA. Infections in diabetic burn patients. Diabetes Care 2004;27:229-233.

9. Jeon MK, Jang YC, Ko JH, Seo DK, Lee JW, Choi JK. A clinical investigation of acute burn in diabetes mellitus patients. J Korean Burn Soc 2008;11:89-91.

10. Thourani VH, Ingram WL, Feliciano DV. Factors affecting success of split-thickness skin grafts in the modern burn unit. J Trauma 2003;54:562-568.

11. Belgian Outcome in Burn Injury Study G. Development and validation of a model for prediction of mortality in patients with acute burn injury. Br J Surg 2009;96:111-117.

12. Osler T, Glance LG, Hosmer DW. Simplified estimates of the probability of death after burn injuries: extending and updating the baux score. J Trauma 2010;68:690-697.

13. Ryan CM, Schoenfeld DA, Thorpe WP, Sheridan RL, Cassem EH, Tompkins RG. Objective estimates of the probability of death from burn injuries. N Engl J Med 1998; 338:362-366.

14. Tobiasen J, Hiebert JM, Edlich RF. The abbreviated burn severity index. Ann Emerg Med 1982;11:260-262.

15. Steinvall I, Bak Z, Sjoberg F. Acute kidney injury is common, parallels organ dysfunction or failure, and carries appreciable mortality in patients with major burns: a prospective exploratory cohort study. Crit Care 2008; 12:R124.

16. Germann G, Barthold U, Lefering R, Raff T, Hartmann B. The impact of risk factors and pre-existing conditions on the mortality of burn patients and the precision of predictive admission-scoring systems. Burns 1997;23:195-203.

17. Li H, Yao Z, Tan J, Zhou J, Li Y, Wu J, et al. Epidemiology and outcome analysis of 6325 burn patients: a five-year retrospective study in a major burn center in Southwest China. Sci Rep 2017;7:46066.

18. Tyson AF, Gallaher J, Mjuweni S, Cairns BA, Charles AG. 
S Kim, et al

The effect of seasonality on burn incidence, severity and outcome in Central Malawi. Burns 2017;43:1078-1082.

19. Englesbe MJ, Pelletier SJ, Magee JC, Gauger P, Schifftner T, Henderson WG, et al. Seasonal variation in surgical outcomes as measured by the American College of Surgeons-National Surgical Quality Improvement Program
(ACS-NSQIP). Ann Surg 2007;246:456-462; discussion 463465.

20. Kinney PL, Schwartz J, Pascal M, Petkova E, Tertre AL, Medina S, et al. Winter season mortality: will climate warming bring benefits? Environ Res Lett 2015;10:064016. 